\title{
Atividade antimicrobiana "in vitro" de compostos a base de hidróxido de cálcio e tergentol em diferentes concentrações sobre bactérias orais ${ }^{1}$
}

\author{
Eduardo José Guerra Seabra², Isabela Pinheiro Cavalcanti Lima² ${ }^{2}$ Sérgio Valmor Barbosa² ${ }^{2}$ Kenio Costa Lima ${ }^{3}$
}

\begin{abstract}
Seabra EJG, Lima IPC, Barbosa SV, Lima KC. Atividade antimicrobiana “in vitro" de compostos a base de hidróxido de cálcio e tergentol em diferentes concentrações sobre bactérias orais. Acta Cir Bras [serial on line] Available from: URL: htt://www.scielo.br/acb.

RESUMO-Objetivos: Este estudo realizado no departamento de Odontologia da Universidade Federal do Rio Grande do Norte foi idealizado com propósito de pesquisar a ação "in vitro" de soluções a base de $\mathrm{Ca}(\mathrm{OH})$ e tergentol frente a bactérias colonizadoras da cavidade bucal e cariogênicas visando contribuir para o estudo sobre os agentes ${ }^{2}$ químicos para controle do biofilme dental. Métodos: Testou-se através de discos de antibiograma e ação em bactérias formadoras de biofilme a ação antimicrobiana de algumas soluções de $\mathrm{Ca}(\mathrm{OH})$ e tergentol usando-se como padrão-ouro o digluconato de clorexidina a $0,12 \%$. Resultados: Os resultados foram analisados atrảavés do teste de Kruskal-Wallis e do pós-teste de comparação múltipla de Dunn com valores de p sempre menores que 0,05. A clorexidina obteve melhores resultados em nível de ação antimicrobiana em relação às soluções a base de $\mathrm{Ca}(\mathrm{OH})$ e tergentol. A diferença estatísta da ação da clorexidina frente às demais soluções e aos tipos bacterianos testados não foi significátiva para a maiorias dos cruzamentos. Conclusões: O digluconato de clorexidina a $0,12 \%$ foi o egente antimicrobiano mais efetivo neste estudo. As soluções a base de hidróxido de cálcio não apresentaram efetividade satisfatória em relação a clorexidina, principalmente em relação ao Streptococcus mutans. São necessários estudos mais aprofundados para se determinar o real potencial do HCT 20 como anti-séptico bucal.
\end{abstract}

DESCRITORES: Hidróxido de cálcio. HCT 20. Controle químico.

\section{Introdução}

A cavidade oral é naturalmente colonizada por vários tipos microbianos, que quando organizados e estruturados compõem a microbiota oral, sendo estas as principais causadoras de duas das patologias orais mais comuns; cárie dentária e doença periodontal. Pode-se afirmar seguramente que o controle da placa bacteriana ou biofilme dentário tem importância ímpar na prevenção, cura e controle destas doenças . Tal controle pode ser realizado mecanicamente ou por intermédio de substâncias químicas. A Odontologia ainda busca aquele que possa ser chamado de "o agente ideal" para o controle químico do biofilme dentário e, visando contribuir para esta área, idealizou-se esta pesquisa.

O HCT 20 é uma solução irrigadora dos canais radiculares que foi desenvolvida por BARBOSA em 1984 composta por Hidróxido de cálcio P.A., tergentol e água destilada. Esta droga vem sendo usada desde então, com bastante sucesso clínico na desinfecção dos canais radiculares por ser dotada de boas propriedades antimicrobianas ${ }^{12,3,6}$, de biocompatibilidade e de tensão superficial atestadas.

A composição do HCT 20 é : 0,2g de hidróxido de cálcio P.A. (pró-análise), $80 \mathrm{ml}$ de água destilada e $20 \mathrm{ml}$ de detergente Tergentol (lauril-dietileno-glicol-éter-sulfato de sódio) a $0,125 \%$. Tal solução foi composta com o intuito de ser uma efetiva solução irrigadora dos canais radiculares, sendo usada nos últimos 17 anos com larga margem de sucesso.
Pimenta $^{8}$ e Seabra ${ }^{10}$ realizaram estudos com o HCT 20 introduzindo o seu uso sob a forma de bochechos, sendo os trabalhos de Seabra ${ }^{10,11}$, um comparativo clínico entre o HCT 20 e a clorexidina em pacientes com gengivite e periodontite onde se obteve com as duas drogas índices de redução do biofilme dentário estatisticamente iguais.

A capacidade antimicrobiana do HCT 20 deve-se ao Hidróxido de cálcio, que é uma substância que tem poder bactericida confirmado por vários estudos ${ }^{6,9}$ e pode ser explicado resumidamente em seu pH, em torno de 12 a 13 (o pH do HCT 20 é $10,8)$, ser considerado incompatível com patógenos orais; e também na penetração de íons cálcio no interior da célula bacteriana inviabilizando seu metabolismo e provocando por conseguinte a morte celular.

A ação do tergentol nesta solução tem vital importância para o seu bom desempenho antimicrobiano. Um detergente, quando adicionado a qualquer solução provoca diminuição da sua tensão superficial ${ }^{5}$, o que acarreta em maior capacidade de difusão desta no interior da massa microbiana organizada com conseqüente maior velocidade no desenvolvimento de sua ação antisséptica.

O HCT 20 foi escolhido para esta pesquisa por tratar-se de uma substância que tem por base de seu princípio atido o hidróxido de cálcio que é uma solução sabidamente biocompatível aos tecidos do hospedeiro e não haver relatos

1. Desenvolvido no Programa de Pós-Graduação em Ciências da Saúde da Universidade Federal do Rio Grande do Norte - UFRN.

2. Do Departamento de Odontologia-UFRN.

3. Prof. Adjunto do Departamento de Odontologia e do Programa de Pós-Graduação em Ciências da Saúde -UFRN. 
de alergia a este composto. Tal fator se constitui numa potencialmente grande vantagem que este material possa apresentar em relação a outros existentes no mercado. A busca pelo composto químico que tenha boa toxicidade seletiva, isto é, a propriedade que uma substância tem de exercer ação danosa apenas sobre os germes causadores da doença, e não sobre células do hospedeiro e nem sobre microrganismos de ação benéfica à saúde bucal.

Sua ação de acordo com Barbosa ${ }^{1,2,3}$, baseia-se na capacidade antimicrobiana do hidróxido de cálcio. Este composto tem sua ação antisséptica e de limpeza facilitadas pelo tergentol. O abaixamento da tensão superficial da solução saturada de hidróxido de cálcio aumenta e acelera a ação antimicrobiana da solução modificando a permeabilidade seletiva da camada externa da célula bacteriana aos íons cálcio e hidroxila devido à dissolução de sua parte lipídica. A penetração destes íons interfere no metabolismo bacteriano.

Portanto, o objetivo deste estudo foi a verificação "in vitro" da capacidade antimicrobiana do HCT 20 e outras concentrações de soluções a base de hidróxido de cálcio e tergentol em dois testes microbiológicos diferentes, estes testes virão a possibilitar um melhor detalhamento sobre o uso potencial do HCT 20 como enxaguatório bucal.

\section{Métodos}

A primeira etapa deste estudo se constituiu na verificação da atividade antimicrobiana através do teste de difusão em agar. Para tanto, utilizou-se cepas padrão de Streptococcus mutans, Streptococcus sanguis, Streptococcus sobrinus e Lactobacillus casei que foram cultivadas e ativadas em meio "Brain Heart Infusion" (B.H.I. -ágar)- (Difco-Detroit- Michigan) com as referidas bactérias incubadas em caldo a $37^{\circ} \mathrm{C}$ por 48 horas em condições de anaerobiose.

As cepas foram semeadas nas placas com o auxílio de swabs estéreis por esgotamento. Logo a seguir, discos de antibiograma estéreis, cada um com 6 milímetros de diâmetro foram embebidos com as soluções teste e dispostos de modo equidistante nas placas com os meios de cultura para posterior verificação dos halos de inibição promovidos por cada solução-teste em milímetros. Foram necessários $0,25 \mathrm{~mL}$ de solução para saturar cada disco.

Após todo esse processo, faz-se necessário que se promova condições de anaerobiose para o crescimento bacteriano em toda a placa semeada, à exceção é claro, dos halos de inibição que pudessem ser formados pelas soluções. Tal anaerobiose foi conseguida através de jarras de Gaspak a $37^{\circ} \mathrm{C}$ por 48 horas para posterior verificação dos halos de inibição em milímetros. Com objetivo de reduzir a variabilidade e conseguir resultados precisos, o experimento foi feito em triplicata para cada microrganismo esolução, exceto o L. casei, que foi feito em duplicata. $\mathrm{O}$ valor dos diâmetros dos halos de inibição foi dado pela média das três repetições.
Este estudo foi idealizado para se verificar a concentração inibitória mínima da associação Hidróxido de cálcio/tergentol, onde se testou várias diluições diferentes, todas com adição do flavorizante aniz (01 gota para cada $30 \mathrm{ml}$ ). As soluçõesteste foram identificadas apenas com números de 01 a 09 que foram obtidos por aleatorização afim de que o operador não tivesse conhecimento de que solução estava sendo aplicada na placa de Petri. A ordem das soluções foi a seguinte:

Solução 1: HCT 20 + flavorizante aniz;

Solução 2: HCT 10 + flavorizante aniz;

Solução 3: HCT 40 + flavorizante aniz;

Solução 4: HCT 20 sem flavorizante;

Solução 5: Água destilada + flavorizante aniz;

Solução 6: HCT 5 + flavorizante aniz;

Solução 7: Tergentol + flavorizante aniz;

Solução 8: Digluconato de clorexidina a $0,12 \%$ + flavorizante aniz;

Solução 9: HCT 30 + flavorizante aniz.

Os números HCT 5,10, 20,30 e 40 representam a proporção de tergentol na solução de água de cal, onde procurou-se saber que diluição da solução a base de hidróxido de cálcio em tergentol (lauril-dietileno-eter-sulfato de sódio a 0,125\%) propiciaria melhor ação antimicrobiana. Sendo que, para se descartar a ação do tergentol, optou-se pelo uso de uma solução-teste com este detergente (solução 7).

A segunda fase do trabalho, também "in vitro", deu-se da seguinte maneira: as mesmas soluções teste da etapa anterior foram confeccionadas e numeradas de 1 a 9 como na etapa anterior, porém com nova aleatorização. Os meios de cultura e as cepas bacterianas usados foram: Streptococcus mutans, Streptococcus sanguis e Streptococcus sobrinus. O que diferiu é que usou-se estas bactérias para testar a ação do HCT 20 em biofilme bacteriano. Estes biofilmes foram produzidos de acordo com o modelo proposto por THROWER et al ${ }^{12}$, onde os biofilmes são produzidos em membranas de filtro de nitrato de celulose de 13 milímetros de diâmetro com 0,22 micrômetros de diâmetro do poro (Milipore Corp., New York- NY). Após 48 horas, um biofilme foi transferido da cultura para um recipiente contendo $10 \mathrm{ml}$ de cada solução teste. Os biofilmes permaneceram em contato com estas soluções por 1 minuto, pois pode ser esta a duração de um bochecho com antisséptico.

Após a permanência do biofilme em contato com a solução pelo tempo determinado ( 1 minuto), transferiu-se cada um para um recipiente contendo $10 \mathrm{ml}$ de água deionizada estéril e homogeneizado em vibrador "vortex" por 1 minuto para ressuspender os microrganismos. Então, transferiu-se $1 \mathrm{ml}$ desta suspensão resultante para $9 \mathrm{ml}$ de solução salina redutora estéril, quando foi diluída. Foram realizadas 07 diluições. Após as diluições, o líquido resultante foi semeado em placas de Petri com meio BHI (experimento feito em triplicata). O número de microrganismos foi então determinado em placas 
de Petri com meio de cultura B.H.I. e incubadas em anaerobiose por 48 horas.

Os biofilmes expostos à solução salina estéril foram tratados similarmente. Transferiu-se $1 \mathrm{ml}$ da amostra de diluente estéril e $1 \mathrm{ml} \mathrm{da}$ suspensão resultante isoladamente para $9 \mathrm{ml} \mathrm{de}$ solução salina redutora estéril e diluída. Foi contado o número de microrganismos para verificar se foram perdidas células dos biofilmes controle.

Ao final deste processo, pôde-se determinar a média do número de unidades formadoras de colônias (UFC) de todos os biofilmes submetidos a cada produto e suas diluições.

Dentro da nova randomização, as soluções e seus números correspondentes foram os seguintes:

Solução 1: digluconato de clorexidina a $0,12 \%$ + flavorizante aniz;

Solução 2: tergentol + flavorizante aniz;
Solução 3: HCT 5 + flavorizante aniz;

Solução 4: Água destilada + flavorizante aniz;

Solução 5: HCT 10 + flavorizante aniz;

Solução 6: HCT 20 sem flavorizante;

Solução 7: HCT 20 + flavorizante aniz;

Solução 8: HCT 30 + flavorizante aniz;

Solução 9: HCT 40 + flavorizante aniz.

\section{Resultados}

No estudo com os discos de antibiogama em placas de Petri, a medição dos halos de inibição provocados pelas soluções testadas obtiveram os seguintes valores médios expressos em milímetros representados no quadro abaixo:

QUADRO 1

\begin{tabular}{|c|c|c|c|c|c|c|c|c|c|c|c|c|c|c|c|c|c|}
\hline & \multicolumn{3}{|c|}{ S. mutans } & \multirow{2}{*}{$\begin{array}{c}\text { Média } \\
\mathbf{0 , 0}\end{array}$} & \multicolumn{3}{|c|}{$\begin{array}{c}\text { S. } \\
\text { sanguis }\end{array}$} & \multirow{2}{*}{\begin{tabular}{|c|} 
Média \\
11,0 \\
\end{tabular}} & \multicolumn{3}{|c|}{$\begin{array}{c}S . \\
\text { sobrinus }\end{array}$} & \multirow{2}{*}{\begin{tabular}{|c|} 
Média \\
$\mathbf{0 , 0}$ \\
\end{tabular}} & \multicolumn{3}{|c|}{ L. casei } & \multirow{2}{*}{\begin{tabular}{|c|} 
Média \\
$\mathbf{0 , 0}$
\end{tabular}} \\
\hline 1 & $\begin{array}{c}\text { HCT } 20 \\
+ \\
\text { Aniz }\end{array}$ & 0 & 0 & 0 & & 12 & 9 & 12 & & 0 & 0 & 0 & & 0 & 0 & 0 & \\
\hline 2 & $\begin{array}{c}\text { HCT } 10 \\
+ \\
\text { Aniz }\end{array}$ & 0 & 0 & 0 & $\mathbf{0 , 0}$ & 4 & 1 & 2 & 2,3 & 0 & 0 & 0 & $\mathbf{0 , 0}$ & 0 & 0 & 0 & $\mathbf{0 , 0}$ \\
\hline 3 & $\begin{array}{c}\text { HCT } 40 \\
+ \\
\text { Aniz }\end{array}$ & 0 & 0 & 0 & $\mathbf{0 , 0}$ & 12 & 12 & 15 & 13 & 0 & 0 & 0 & 0,0 & 0 & 0 & 0 & $\mathbf{0 , 0}$ \\
\hline 4 & HCT 20 & 0 & 0 & 0 & $\mathbf{0 , 0}$ & 9 & 8 & 10 & 9,0 & 0 & 0 & 0 & $\mathbf{0 , 0}$ & 0 & 0 & 0 & $\mathbf{0 , 0}$ \\
\hline 5 & $\begin{array}{c}\text { Água } \\
\text { destilada } \\
+ \text { Aniz }\end{array}$ & 0 & 0 & 0 & $\mathbf{0 , 0}$ & 0 & 0 & 0 & 0,0 & 0 & 0 & 0 & 0,0 & 0 & 0 & 0 & $\mathbf{0 , 0}$ \\
\hline 6 & $\begin{array}{c}\text { HCT } 5+ \\
\text { Aniz } \\
\end{array}$ & 0 & 0 & 0 & $\mathbf{0 , 0}$ & 0 & 0 & 0 & 0,0 & 0 & 0 & 0 & 0,0 & 0 & 0 & 0 & 0,0 \\
\hline 7 & $\begin{array}{c}\text { Tergentol } \\
+ \\
\text { Aniz } \\
\end{array}$ & 5 & 4 & 4 & 4,3 & 15 & 12 & 15 & 14,0 & 5 & 4 & 4 & 4,6 & 11 & 9 & 12 & 10,6 \\
\hline 8 & $\begin{array}{c}\text { Clorex. + } \\
\text { Aniz } \\
\end{array}$ & 14 & 11 & 11 & 12,0 & 17 & 13 & 18 & 16,0 & 10 & 10 & 14 & 11,3 & 16 & 14 & 15 & 15,0 \\
\hline 9 & $\begin{array}{c}\text { HCT } 30 \\
+ \text { Aniz }\end{array}$ & 0 & 0 & 0 & $\mathbf{0 , 0}$ & 10 & 11 & 13 & 11,3 & 0 & 0 & 0 & 0,0 & 0 & 0 & 0 & $\mathbf{0 , 0}$ \\
\hline
\end{tabular}

Fonte: Programa de Pós-Graduação em Ciências da Saúde-UFRN. 2005 
O quadro abaixo mostra o desempenho das soluções em valores de halos de inibição mínimos, máximos e mediana (em milímetros):

QUADRO 2

\begin{tabular}{|c|c|c|c|c|c|}
\hline & Solução & Medições & Mediana & Mínimo & Máximo \\
\hline 1 & HCT 20 + aniz & 12 & 0.000 & 0.000 & 12.000 \\
\hline 2 & HCT 10 + aniz & 12 & 0.000 & 0.000 & 4.000 \\
\hline 3 & HCT 40 + aniz & 12 & 0.000 & 0.000 & 15.000 \\
\hline 4 & Água destilada + aniz & 12 & 0.000 & 0.000 & 0.000 \\
\hline 5 & HCT 5 + aniz & 12 & 0.000 & 0.000 & 0.000 \\
\hline 6 & Tergentol + aniz & 12 & 7.000 & 4.000 & 15.000 \\
\hline 7 & Clorexidina & 12 & 14,000 & 10.000 & 18.000 \\
\hline 8 & HCT 30 + aniz & 12 & 0.000 & 0.000 & 13.000 \\
\hline 9 & HCT 20 + aniz & 12 & 0.000 & 0.000 & 10.000 \\
\hline
\end{tabular}

Fonte: Programa de Pós-Graduação em Ciências da Saúde-UFRN. 2005

Foi aplicado o teste de Kruskal-Wallis e o valor de "p" obtido para este teste foi de $\mathrm{p}<0,0001$ para todas as bactérias juntas, sendo considerado pois, extremamente significante.
No teste com o biofilme, foi aplicado o teste de Kruskal-Wallis e o pós-teste de Comparação múltipla de Dunn. Os resultados estão expostos nos quadros abaixo:

Para S. sanguis: (número de Unidades Formadoras de Colônias -UFC) em log de 10

QUADRO 3

\begin{tabular}{|c|c|c|c|c|c|c|}
\hline & Solução & $\begin{array}{c}\text { Teste de } \\
\text { Dunn }\end{array}$ & Mediana & Mínimo & Máximo & $\begin{array}{c}\text { Valor de } \\
\text { p }\end{array}$ \\
\hline 1 & Clorexidina + aniz & $\mathrm{A}$ & 8.000 & 8.000 & 8.600 & \multirow{9}{*}{0,0016} \\
\hline 2 & Tergentol + aniz & $\mathrm{B}$ & 11.370 & 11.370 & 11.260 & \\
\hline 3 & HCT 5 + aniz & A, B & 9.960 & 9.460 & 10.060 & \\
\hline 4 & $\begin{array}{c}\text { Água destilada }+ \\
\text { aniz }\end{array}$ & A, B & 9.750 & 9.480 & 9.870 & \\
\hline 5 & HCT 10 + aniz & $\mathrm{A}, \mathrm{B}$ & 10.900 & 10.850 & 10.910 & \\
\hline 6 & HCT 20 sem aniz & $\mathrm{A}, \mathrm{B}$ & 11.060 & 10.850 & 11.220 & \\
\hline 7 & HCT $20+$ aniz & A, B & 9.920 & 9.840 & 9.930 & \\
\hline 8 & HCT 30 + aniz & $\mathrm{A}, \mathrm{B}$ & 10.220 & 10.170 & 10.220 & \\
\hline 9 & HCT 40 + aniz & $\mathrm{A}, \mathrm{B}$ & 10.740 & 10.700 & 10.740 & \\
\hline
\end{tabular}

Fonte: Programa de Pós-Graduação em Ciências da Saúde-UFRN. 2005 
Para S.mutans: (número de Unidades Formadoras de Colônias

-UFC) em log de 10

QUADRO 4

\begin{tabular}{|c|c|c|c|c|c|c|}
\hline & Solução & $\begin{array}{c}\text { Teste de } \\
\text { Dunn }\end{array}$ & Mediana & Mínimo & Máximo & $\begin{array}{c}\text { Valor de } \\
\text { p }\end{array}$ \\
\hline 1 & Clorexidina + aniz & $\mathrm{A}$ & 0.000 & 0.000 & 0.000 & \multirow{9}{*}{0,0015} \\
\hline 2 & Tergentol + aniz & $\mathrm{B}$ & 11.160 & 11.020 & 11.130 & \\
\hline 3 & HCT $5+$ aniz & B & 10.950 & 10.910 & 11.030 & \\
\hline 4 & $\begin{array}{l}\text { Água destilada + } \\
\text { aniz }\end{array}$ & $\mathrm{A}, \mathrm{B}$ & 9.170 & 9.110 & 9.250 & \\
\hline 5 & HCT 10 + aniz & $\mathrm{A}, \mathrm{B}$ & 8.600 & 8.470 & 8.840 & \\
\hline 6 & HCT 20 sem aniz & $\mathrm{A}, \mathrm{B}$ & 9.460 & 9.360 & 9.560 & \\
\hline 7 & HCT 20 + aniz & $\mathrm{A}, \mathrm{B}$ & 10.190 & 10.140 & 10.300 & \\
\hline 8 & HCT $30+$ aniz & $\mathrm{A}, \mathrm{B}$ & 8.470 & 8.000 & 8.470 & \\
\hline 9 & HCT $40+$ aniz & $\mathrm{A}, \mathrm{B}$ & 8.470 & 8.300 & 8.770 & \\
\hline
\end{tabular}

Fonte: Programa de Pós-Graduação em Ciências da Saúde-UFRN. 2005

Para S.sobrinus: (número de Unidades Formadoras de

Colônias-UFC) em log de 10

QUADRO 5

\begin{tabular}{|c|c|c|c|c|c|c|}
\hline & Solução & $\begin{array}{c}\text { Teste de } \\
\text { Dunn }\end{array}$ & Mediana & Mínimo & Máximo & $\begin{array}{c}\text { Valor de } \\
\text { p }\end{array}$ \\
\hline 1 & Clorexidina + aniz & $\mathrm{A}$ & 9.250 & 9.170 & 9.300 & \multirow{9}{*}{0,0021} \\
\hline 2 & Tergentol + aniz & $\mathrm{A}, \mathrm{B}$ & 9.200 & 9.200 & 6.610 & \\
\hline 3 & HCT 5 + aniz & $\mathrm{A}, \mathrm{B}$ & 10.450 & 10.360 & 10.470 & \\
\hline 4 & $\begin{array}{c}\text { Água destilada }+ \\
\text { aniz }\end{array}$ & A,B & 10.350 & 10.190 & 10.410 & \\
\hline 5 & HCT 10 + aniz & $\mathrm{A}, \mathrm{B}$ & 10.410 & 10.400 & 10.560 & \\
\hline 6 & HCT 20 sem aniz & $\mathrm{A}, \mathrm{B}$ & 11.130 & 11.080 & 11.160 & \\
\hline 7 & HCT 20 + aniz & $\mathrm{B}$ & 11.350 & 11.190 & 11.440 & \\
\hline 8 & HCT $30+$ aniz & $\mathrm{A}, \mathrm{B}$ & 10.670 & 10.590 & 10.780 & \\
\hline 9 & HCT 40 + aniz & $\mathrm{A}, \mathrm{B}$ & 10.480 & 10.400 & 10.480 & \\
\hline
\end{tabular}

Fonte: Programa de Pós-Graduação em Ciências da Saúde-UFRN. 2005

\section{Discussão}

Os resultados da análise feita nos ensaios com as Placas de Petri e os discos de antibiograma mostraram extrema superioridade na capacidade antimicrobiana do digluconato de clorexidina a $0,12 \%$ sobre os quatro tipos bacterianos testados, seja no colonizador inicial, que é o Streptococcus sanguis, ou nas bactérias cariogênicas (Streptococcus mutans, Streptococcus sobrinus e Lactobacillus casei ). Apesar da metodologia e o tipo de análise diferirem da literatura sobre o HCT $20,8,10$ a clorexidina se mostrou consideravelmente superior ao HCT 20, seja na forma convencional ou adicionada do flavorizante aniz, o que não ocorreu nos estudos supracitados.
Tal diferença metodológica também chamou atenção dos autores em relação aos trabalhos apresentados por Barbosa ${ }^{1,2,3}$, pois no presente estudo, a ação antimicrobiana do HCT 20 só foi satisfatória frente ao Streptococcus sanguis, não tendo obtido halo de inibição de crescimento bacteriano algum para os outros tipos bacterianos testados. Pensou-se na hipótese desta diferença importante na qualidade de ação antibacteriana do HCT 20 estar em algum tipo de reação negativa do Hidróxido de Cálcio do HCT 20 e das demais concentrações de tergentol nas soluções de HCT com o ágar presente no meio de cultura utilizado neste experimento. Hipótese esta que tem como contraposição o fato de todas as concentrações do HCT $(5,10,20,30$ e $40 \%$ de tregentol) terem induzido a formação de halos de inibição contra o Streptococcus sanguis. 
Tomando-se por base apenas esta metodologia de experimentação, poder-se-ia raciocinar equivocadamente que o HCT 20 só seria efetivo frente a bactérias colonizadoras iniciais, sendo ineficazes contra bactérias cariogênicas. Além do que, devido a desvantagem que ele apresentou em relação à clorexidina, não valeria a pena continuar desenvolvendo estudos sobre o uso do HCT 20 como anti-séptico bucal. Mas é preciso testar todas as possibilidades para se fazer qualquer tipo de afirmação com verdade científica. Então, somando-se este raciocínio à possível reação do $\mathrm{Ca}(\mathrm{OH})$ com o ágar, levou-se este estudo adiante para testar es mesmas soluções com as mesmas cepas bacterianas com o biofilme, condição tal que simula com mais precisão um bochecho com enxaguatório bucal, bem como isenta as soluções-teste do contato com o ágar.

Analisando-se agora os testes feitos com as bactérias formadoras de biofilme, ao se realizar o cruzamento dos testes em cada solução, a clorexidina apresentou os melhores resultados para com os Streptococcus mutans e os Streptococcus sanguis, tendo havido resultados semelhantes ao tergentol para Streptococcus sobrinus.

O HCT 20, assim como no teste com os discos de antibiograma, apresentou os melhores resultados contra o Streptococcus sanguis. Se compararmos o HCT 20 puro e com flavorizante à clorexidina, o pós-teste de Dunn só revelou diferença estatisticamente significante $(\mathrm{p}<0,05)$ para suas ações contra o Streptococcus sobrinus, mesmo com a ação inibitória total de crescimento bacteriano que somente a clorexidina desempenhou frente ao Streptococcus mutans.

Os achados deste experimento direcionam ao pensamento de que a ação antimicrobiana das soluções a base de hidróxido de cálcio e tergentol pode estar relacionada à proporção do detergente na solução. Estas soluções não tiveram desempenho esperado conforme a literatura sobre o assunto nos mostra, mas vale frisar que esta metodologia foi diferente, além do que, a ação no teste do biofilme da água destilada que deveria ter sido a pior, foi estatisticamente próxima, e por vezes até melhor, que as soluções a base de hidróxido de cálcio.

\section{Conclusões}

O digluconato de clorexidina a $0,12 \%$ foi o egente antimicrobiano mais efetivo neste estudo.

Não houve diferença estatística significativa entre as ações das soluções a base de $\mathrm{Ca}(\mathrm{OH})$ e a ação parecia melhorar conforme o percentual de detergente ia aumentando.

As soluções a base de hidróxido de cálcio não apresentaram efetividade satisfatória em relação à clorexidina, principalmente em relação ao Streptococcus mutans.
São necessários estudos mais aprofundados para se determinar o real potencial do HCT 20 como anti-séptico bucal.

\section{Referências}

1. Barbosa SV Atividade antimicrobiana da solução de hidróxido de cálcio pura e em associação com detergente sobre microrganismos dos canais radiculares. [Dissertação de mestrado]. Universidade Federal do Rio Grande do Norte- Departamento de Odontologia; 1984.

2. Barbosa SV, Almeida D Uma solução irrigadora para canais radiculares humanos. Rev Bras Odont 1987; 44: 21-8.

3. Barbosa SV, Spangberg LSW, Almeida D Low surface tension calcium hydroxide is na effective antiseptic. Int Endod J 1994; 27 : 06-10.

4. Cury JA Controle químico da placa dental In: ABOPREV. Promoção de saúde bucal. São Paulo: Artes médicas, 1997: Cap. 7, p. 129-140.

5. Feirer WA, Leonard V Hexylresorcinol in oral antisepsis with special reference to solution ST 37. Dent Cosmos 1927; 69: 882892.

6. Georgopoulou M, Kontakiotis E, Nakou M "In vitro" evaluation of the effectiveness of calcium hydroxide and paramonochlorophenol on anaerobic bacteria from the root canal. Endod Dent Traumatol 1993; 9: 249-253.

7. Lima KC de Atividade antimicrobiana de solução de fluoreto de sódio e clorexidina na cavidade oral: aspectos ecológicos, metabólicos e eficácia clínica. [Tese de doutorado]. Universidade Federal do Rio de Janeiro; 2001.

8. Pimenta FH, Barbosa SV A eficácia do HCT 20 como agente antiplaca. Rev ABO 1998; 6 : 33-36.

9. Safavi KE, Nichols FC Effect os calcium hydroxyde on bacterial lipopolysaccharide. J Endod 1993; 12: 76-78.

10. Seabra EJG Estudo comparativo da atividade de redução do índice de placa bacteriana entre o digluconato de clorexidina a $0,12 \%$ e o HCT 20 em soluções para bochechos em pacientes portadores de gengivite e periodontite crônicas. [Dissertação de mestrado]. Universidade Federal do Rio Grande do Norte- Departamento de Odontologia; 1999.

11. Seabra EJG, Barbosa SV, Seabra EG Redução da placa bacteriana com o uso da clorexidina e HCT 20 em pacientes com gengivite e periodontite crônicas. Robrac 2000; 9:13-17.

12. Thrower Y, Pinney RJ, Wilson M Susceptibities of Actinobacillus actinomicetencomitans biofilms to oral antiseptics. J Med Microbiol 1997; 46: 425-429.

13. Vieira AMGS Atividade antimicrobiana de anti-sépticos orais e dentifrícios para bebês: um estudo sobre células sésseis e planctônicas. [Tese de doutorado]. Universidade Federal do Rio de Janeiro; 1999. 
Seabra EJG, Lima IPC, Barbosa SV, Lima KC. Antimicrobial activity "in vitro" of calcium hydroxide and tergentol on different concentrations in oral bactéria. Acta Cir Bras [serial on line] Available from: URL: htt://www.scielo.br/acb.

ABSTRACT - Purposes: This research desenvolved in Rio Grande do Norte Federal University, Department of Dentistry purpose evaluation "in vitro" $\mathrm{Ca}(\mathrm{OH})$ and tergentol solutions action in oral cavity that first reside in and cariogenic microorganisms for dental biofilm chemical control increasing. Methods: "In vitro" tests with antibiogram discs and biofilm formers bacteria antibiothic action from $\mathrm{Ca}(\mathrm{OH})$ and tergentol solutions and the $0,12 \%$ clorhexydine digluconate as "gold-standard". Results: The results were analyzed using the Kruskal-Wallis test and Dunn's multiple comparison post-test with p-value always lower than 0,05 . The clorhexydine showed a better antimibrobian action in correlation with $\mathrm{Ca}(\mathrm{OH})$ and tergentol solutions. The statistical differences among clorhexydine and this study other solutions was not significant in a greater part of comparisons. Conclusons: The 0,12\% clorhexydine digluconate was the most effective antibiotic agent in this research. $\mathrm{Ca}(\mathrm{OH})$ and tergentol solutions does not demonstrate satisfactory effectiveness in correlation the clorhexydine, mainly, for the Streptococcus mutans. More complete studies are necessary for CHD 20 evaluation as an oral antiseptic.

KEYWORDS: Calcium hydroxide. CHD 20. Chemical control.

Correspondência:

Departamento de Odontologia-UFRN

Av. Salgado Filho, Natal-RN

Conflito de interesses: nenhum

Fonte de financiamento: nenhuma 